\title{
Likelihood-based specification analysis of continuous-time models of the short-term interest rate ${ }^{\text {tr }}$
}

\author{
Garland B. Durham ${ }^{\mathrm{a}, *}$ \\ ${ }^{a}$ Department of Economics, University of Iowa, Iowa City, IA 52242-1000, USA
}

\begin{abstract}
An extensive collection of continuous-time models of the short-term interest rate is evaluated over data sets that have appeared previously in the literature. The analysis, which uses the simulated maximum likelihood procedure proposed by Durham and Gallant (2002), provides new insights regarding several previously unresolved questions. For single factor models, I find that the volatility, not the drift, is the critical component in model specification. Allowing for additional flexibility beyond a constant term in the drift provides negligible benefit. While constant drift would appear to imply that the short rate is nonstationary, in fact, stationarity is volatility-induced. The simple constant elasticity of volatility model fits weekly observations of the three-month Treasury bill rate remarkably well but is easily rejected when compared with more flexible volatility specifications over daily data. The methodology of Durham and Gallant can also be used to estimate stochastic volatility models. While adding the latent volatility component provides a large improvement in the likelihood for the physical process, it does little to improve bond-pricing performance.
\end{abstract}

${ }^{\text {in }}$ I am grateful for the helpful comments and suggestions of Evan Anderson, Tim Bollerslev, Frank Diebold, John Geweke, Eric Ghysels, Chris Jones, George Tauchen, an anonymous referee, and especially Ronald Gallant. Any remaining errors are my own.

*Corresponding author.

E-mail address: garland-durham@uiowa.edu (G.B. Durham). 


\section{Introduction}

Understanding the dynamics of the short-term interest rate is of fundamental importance for many financial applications. Although these data have been subjected to extensive analysis, some basic issues remain unresolved. This may stem in part from the difficulties associated with the statistical analysis of continuous-time processes.

However, a great deal of progress has been made recently in developing efficient tools for estimating and testing continuous-time models. In this paper, I use some of these tools to evaluate the performance of various models of the short rate. The analysis serves as an illustration of the new techniques, while at the same time shedding new light on several issues of interest.

I begin by examining scalar models of the short rate. The models are defined in terms of a stochastic differential equation (SDE) of the form

$$
\mathrm{d} X=\mu(X ; \theta) \mathrm{d} t+\sigma(X ; \theta) \mathrm{d} W .
$$

I follow the standard procedure of looking at a nested sequence of models. The innovation is that I am able to compute maximum likelihood estimates, test hypotheses using likelihood ratio statistics, and rank the models in terms of various information criteria. Some of my results differ dramatically from previous findings in the literature and are of particular interest given the well-known optimality properties of likelihood-based techniques.

The difficulty is that the likelihood function is not available in closed form for most models, and so one is required to approximate it. The simulation approach suggested by Pedersen (1995) and Santa-Clara (1995) (see also Brandt and SantaClara, 2002), which is based on integrating out unobserved states of the process between each pair of observations, has great intuitive appeal. However, implementations available until recently have been computationally burdensome. Durham and Gallant (2002) examine a number of numerical techniques and find that the convergence of the simulation-based method can be greatly accelerated. Using these techniques, very accurate approximations can be quickly and conveniently obtained to the maximum likelihood estimator across a wide range of continuous-time models. This is the approach used in this paper.

While being able to efficiently fit and test scalar models is an essential first step, short-term interest rates (along with many other financial time series) are known to exhibit properties such as fat tails and volatility persistence that are inconsistent with these models (see, e.g., Ghysels et al., 1996). Thus I also examine several stochastic volatility models of the form

$$
\begin{aligned}
& \mathrm{d} X=\mu_{X}(X)+\sigma_{X}(X) \exp (H) \mathrm{d} W_{1} \\
& \mathrm{~d} H=\mu_{H}(H) \mathrm{d} t+\sigma_{H}(H) \mathrm{d} W_{2} .
\end{aligned}
$$

Durham and Gallant (2002) show that the simulation-based approach can be extended to approximate the likelihood of these models.

The econometric techniques used in this paper are closely related to the Markov Chain Monte Carlo methods used by Eraker (2001), Jones (1999), Elerian et al. 
(2001), and Kim et al. (1998). These authors also simulate sample paths across unobserved intermediates points between each pair of observations, but within a Bayesian instead of maximum likelihood framework.

An alternative approach to maximum likelihood estimation of the scalar diffusion models described by Eq. (1) has been proposed by Aït-Sahalia (2001). This approach approximates the transition density using Hermite expansions calibrated to match approximate model moments. While Ait-Sahalia's approach can be useful for some models, it is of little help for many of the models examined in this paper. In particular, it requires that the integral $\int 1 / \sigma(x ; \theta) \mathrm{d} x$ be available in closed form, which is often not the case. Also, the approach cannot be used for multivariate or latent variable models such as Eq. (2).

The empirical work builds on a large body of literature. Chan et al. (1992) examine a number of models that can be nested within the class

$$
\mathrm{d} X=(\alpha+\beta X) \mathrm{d} t+\kappa X^{\gamma} \mathrm{d} W .
$$

The specification $\sigma(x)=\kappa x^{\gamma}$ is commonly referred to as constant elasticity of volatility (CEV). Chan et al. obtain estimates using the generalized method of moments (GMM) on the discrete-time (Euler) approximation to the SDE. Using monthly observations of the one-month Treasury bill rate from June 1964 to December $1989(N=307)$, they find that the mean reversion parameter $\beta$ is insignificantly different from zero and that the volatility function is the critical component in model specification. The drawback of this approach is that estimates based on the discrete-time approximation are known to be biased (see, e.g., Elerian et al., 2001). The GMM estimator used by Chan et al. is also inefficient (for example, their standard error on the estimate of $\kappa$ is so large that the parameter is not significantly different from zero).

Ait-Sahalia (1996) tests parametric models of the short rate by comparing the unconditional density implied by the model to a nonparametric estimate of the empirical density of the data. He uses a larger encompassing model,

$$
\mathrm{d} X=\left(\alpha_{1}+\alpha_{2} X+\alpha_{3} X^{2}+\alpha_{4} / X\right) \mathrm{d} t+\left(\beta_{1}+\beta_{2} X+\beta_{3} X^{\beta_{4}}\right)^{1 / 2} \mathrm{~d} W,
$$

and daily observations of the seven-day Eurodollar rate from June 1, 1973 to February 25, $1995(N=5,505)$. Aït-Sahalia finds that strong evidence exists for nonlinearity in the drift; that this nonlinearity makes the process stationary; that the volatility function is lowest for interest rates around $10 \%$ and higher at both extremes; and that the drift, not the volatility function, is the critical element in model specification.

Conley et al. (1997) use an estimation procedure based on moment conditions obtained using the infinitesimal generator and a collection of test functions. They look at daily observations of the federal funds overnight interest rate from January 2, 1970 to January 29, 1997. While this paper is often cited as finding evidence in favor of nonlinearity, in fact, the results are ambiguous. If the parameter governing the elasticity of volatility is fixed at around $1.5-2$, which is the range for which they find the most support, then little evidence of nonlinearity in the drift is found. The 
authors point out that stationarity depends not only on the drift but on the volatility function as well.

Tauchen (1995) uses the efficient method of moments estimator with data composed of weekly observations of the 30-day Eurodollar rate from January 3, 1975 to October 28, $1994(N=1,035)$. His results corroborate Aït-Sahalia's finding of nonlinearity in the drift.

Both Conley et al. (1997) and Tauchen (1995) use the encompassing model

$$
\mathrm{d} X=\left(\alpha_{1}+\alpha_{2} X+\alpha_{3} X^{2}+\alpha_{4} / X\right) \mathrm{d} t+\beta_{1} X^{\beta_{2}} \mathrm{~d} W .
$$

That is, they allow for nonlinearity in the drift but use a relatively restrictive volatility specification. Both papers find the criterion function to be flat in the direction of $\beta_{2}$, making precise estimation of this parameter difficult.

Stanton (1997) obtains nonparametric estimates of the drift and diffusion using daily observations of the three-month Treasury bill rate from January 4, 1965 to July 28,1995 . He, too, finds evidence of substantial nonlinearity in the drift.

However, Pritsker (1998) examines the specification test of Ait-Sahalia (1996) and finds that it rejects true models too often. If the size of the test is corrected, then it has little power. Chapman and Pearson (2000) find that the estimators used by AitSahalia (1996) and Stanton (1997) are prone to find evidence of nonlinearity where none exists (because of small-sample bias). And finally, Jones (2003b) uses Bayesian techniques to conclude that whether or not one finds nonlinearity in the drift of the short rate may depend largely on the prior that is used.

The upshot of all this is that a great deal of uncertainty remains regarding how to appropriately specify even simple scalar models of the short rate. Attention has focused primarily on the drift component. While most authors favor nonlinearity in the drift, recent work has raised interesting questions. Also, while Aït-Sahalia (1996) finds compelling evidence in favor of a more flexible volatility specification, other studies have remained within the CEV framework.

Going beyond the class of scalar models, one encounters a bewildering array of multifactor alternatives, ranging from the two-factor stochastic volatility models studied by Gallant and Tauchen (1998) and Andersen and Lund (1997) to models with several unobserved factors, possibly including jump components (e.g., Ahn et al., 2002; Boudoukh et al., 1998; Chacko, 1996; Dai and Singleton, 2000; Duffie and Kan, 1996). This paper considers models of the form given by Eq. (2), which includes the models studied by Gallant and Tauchen (1998) and Andersen and Lund (1997) as special cases.

Models are evaluated over several of the data sets used in previous studies: daily observations of the seven-day Eurodollar interest rate (Aït-Sahalia, 1996), daily observations of the three-month Treasury bill rate (Stanton, 1997), and weekly observations of the three-month Treasury bill rate (Gallant and Tauchen, 1998). This allows my results to be directly compared with the existing literature.

I find no significant evidence of nonlinearity in the drift. I do not even find the linear term to be significant. While constant drift would appear to result in a nonstationary process, it turns out that stationarity is volatility-induced (see also Conley et al., 1997). The volatility function is the critical component of model 
specification; the choice of drift function is largely irrelevant. In contrast to some of the existing literature, I am able to estimate the parameters of the volatility function precisely. Although the CEV specification works remarkably well for weekly observations of the three-month Treasury bill rate, it is soundly rejected over both sets of daily data by models using a more flexible volatility specification.

The seven-day Eurodollar data appear to be very noisy and are probably not a reliable proxy for the true short rate. These data exhibit volatility roughly twice that of either of the Treasury bill data sets. While this may not make much difference for bond pricing, it will be important for pricing securities that depend more critically on the volatility of the short rate and lends additional credence to the idea that the choice of proxy used for short-rate modeling can have important consequences (see also Chapman et al., 1999).

Some authors have proposed models in which the short rate fluctuates about a slow-moving target rate (see, e.g., Balduzzi et al., 1998; Bass and Farnsworth, 2000). Such models may provide an explanation for the shortcomings of the CEV model over daily data and may be especially useful in dealing with very short-term rates such as the seven-day Eurodollar.

Introducing a stochastic volatility factor results in a huge jump in the likelihood over the scalar models. The findings for the drift of the short rate carry over unchanged from the scalar case; that is, I again find negligible evidence in favor of including anything beyond a constant term. In contrast to Andersen and Lund (1997), I do not find that including a stochastic volatility component substantially changes the estimated elasticity of volatility.

The paper concludes by looking at implications of some of these models for bond pricing. Risk-neutral models are estimated by minimizing mean squared pricing errors for bonds with one, two, five, and 10-year maturities. Computing bond prices implied by the stochastic volatility (SV) model requires estimates of the spot volatility. A convenient feature of the estimation methodology used in this paper is that estimates for the spot volatility are readily available.

As with the physical process, little evidence exists in favor of including terms beyond the constant in the drift of the risk-neutral process. While stochastic volatility is certainly important for modeling the dynamics of the short rate and will likely be important for pricing fixed-income securities with a more option-like character, it is of limited usefulness in explaining bond prices.

The remainder of this paper is organized as follows: Section 2 examines scalar models of the short rate, Section 3 considers stochastic volatility models, Section 4 looks at implications for bond prices, and Section 5 concludes.

\section{Scalar models of the short rate}

This section evaluates the performance of a variety of scalar models of the U.S. short-term interest rate over three data sets that have appeared previously in the literature. The first data set was used by Gallant and Tauchen (1998) and consists of 1,809 weekly observations (January 5, 1962-August 30, 1996) of the three-month 
Treasury bill rate in the secondary market. Rates are annualized and quoted on a discount basis. Friday rates are used when available, otherwise the Thursday rate is used. The second data set was used by Stanton (1997) and consists of 7,555 daily observations (January 4, 1965-July 28, 1995) of the three-month Treasury bill rate. Quotes are converted from discounts to annualized interest rates. The third was used by Aït-Sahalia (1996) and consists of 5,505 daily observations (June 1, 1973February 25, 1995) of the seven-day Eurodollar deposit spot rate. The bid-ask midpoint is used. No adjustments are made for weekends or holidays in either of the daily data sets. The data are plotted in Fig. 1.

The model specifications considered are displayed in Table 1. They include the affine model (e.g., Dai and Singleton, 2000), the constant elasticity of volatility model (e.g., Conley et al., 1997), and the preferred model of Aït-Sahalia (1996). Note
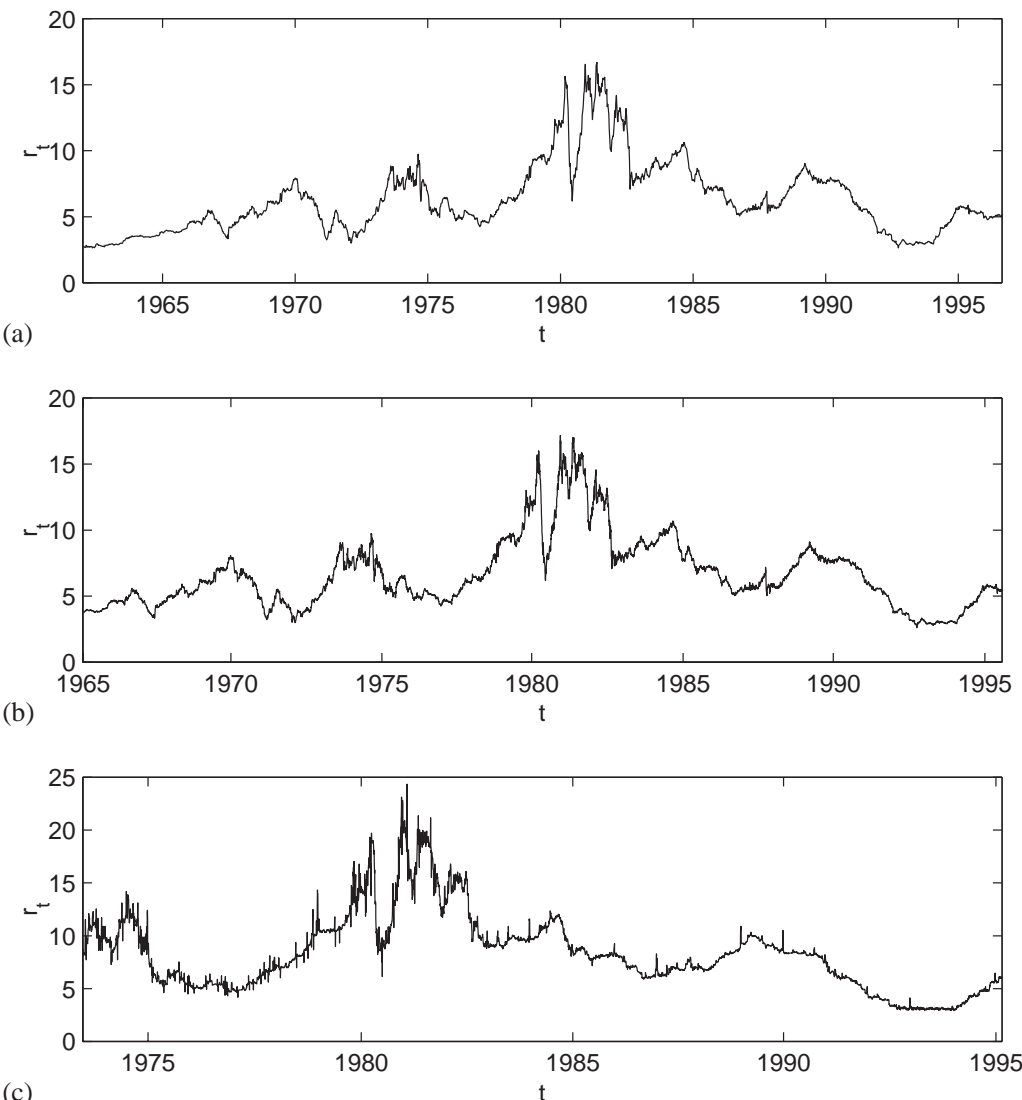

Fig. 1. Scalar models of the U.S. short-term interest rate over three data sets: (a) weekly observations of three-month Treasury bill rate, January 5, 1962 to August 30, 1996; (b) daily observations of three-month Treasury bill rate, January 4, 1965 to July 28, 1995; and (c) daily observations of seven-day Eurodollar rate, June 1, 1973 to February 25, 1995. 
Table 1

Scalar model specifications for short rate

The specifications of each of the models considered in this section are shown together with the labels by which they are referred in the text. AFF is the affine model. CEV1, CEV2, and CEV4 are constant of elasticity of volatility models with various drift specifications. GEN1, GEN2, and GEN4 use a more general volatility specification together with various drift specifications.

\begin{tabular}{ll}
\hline AFF: & $\mathrm{d} X=\left(\alpha_{1}+\alpha_{2} X\right) \mathrm{d} t+\left(\beta_{1}+\beta_{2} X\right)^{1 / 2} \mathrm{~d} W$ \\
CEV1: & $\mathrm{d} X=\alpha_{1} \mathrm{~d} t+\beta_{1} X^{\beta_{2}} \mathrm{~d} W$ \\
CEV2: & $\mathrm{d} X=\left(\alpha_{1}+\alpha_{2} X\right) \mathrm{d} t+\beta_{1} X^{\beta_{2}} \mathrm{~d} W$ \\
CEV4: & $\mathrm{d} X=\left(\alpha_{1}+\alpha_{2} X+\alpha_{3} X^{2}+\alpha_{4} / X\right) \mathrm{d} t+\beta_{1} X^{\beta_{2}} \mathrm{~d} W$ \\
& \\
GEN1: & $\mathrm{d} X=\alpha_{1} \mathrm{~d} t+\left(\beta_{1}+\beta_{2} X+\beta_{3} X^{\beta_{4}}\right)^{1 / 2} \mathrm{~d} W$ \\
GEN2: & $\mathrm{d} X=\left(\alpha_{1}+\alpha_{2} X\right) \mathrm{d} t+\left(\beta_{1}+\beta_{2} X+\beta_{3} X^{\beta_{4}}\right)^{1 / 2} \mathrm{~d} W$ \\
GEN4: & $\mathrm{d} X=\left(\alpha_{1}+\alpha_{2} X+\alpha_{3} X^{2}+\alpha_{4} / X\right) \mathrm{d} t+\left(\beta_{1}+\beta_{2} X+\beta_{3} X^{\beta_{4}}\right)^{1 / 2} \mathrm{~d} W$
\end{tabular}

that the affine model subsumes the Ornstein-Uhlenbeck model proposed by Vasicek (1977) and the square-root model proposed by Cox et al. (1985) as special cases.

Although stochastic differential equations provide a convenient way to describe the dynamics of interest rates and other financial data, finding effective ways to estimate these models has proven to be a difficult task.

A variety of moment-based approaches have been proposed, including Chan et al. (1992), Duffie and Singleton (1993), Gallant and Tauchen (1997), Bibby and Sørensen (1995), Gouriéroux et al. (1993), Hansen and Scheinkman (1995), and Duffie and Glynn (1996). Bayesian techniques using Markov Chain Monte Carlo methods have been proposed by Eraker (2001), Jones (1999), and Elerian et al. (2001).

However, maximum likelihood estimation has desirable optimality properties and is the approach that I shall use in this paper. The transition density is generally not available in closed form, so the problem is to approximate it efficiently. Pedersen (1995) and Santa-Clara (1995) propose a simulation approach (SMLE) based on integrating out intermediate unobserved states of the process between each pair of observations (see Brandt and Santa-Clara, 2002 for a multivariate application). Florens-Zmirou (1989) suggests using the first-order Gaussian approximation of the process. Shoji and Ozaki (1998), Kessler (1997), Elerian (1998), Nowman (1997), and Ait-Sahalia $(1999,2001)$ provide a variety of closed-form improvements to this firstorder approximation.

Although the simulation-based approach has great intuitive appeal, it can be computationally burdensome. Durham and Gallant (2002) examine a variety of numerical techniques that greatly accelerate its convergence. Using synthetic data generated by a Cox-Ingersoll-Ross (CIR) model calibrated to match monthly observations of the U.S. short-term interest rate as a test case, they find that the log likelihood function may be approximated with negligible error for $N=10,000$ observations in about one second on a $750 \mathrm{MHz}$ PC. This approach allows accurate maximum likelihood estimates to be obtained quickly and conveniently and is the one that I shall employ in this paper. 
The preferred model of Aït-Sahalia (1996) is GEN4. All of the scalar models that I consider may be nested within this specification, allowing the use of conventional means of specification testing. Since likelihoods are available for all of the models, the likelihood ratio (LR) test can be applied. This test is known to have attractive optimality properties (see, e.g., Lehmann, 1986). I also rank the models in terms of the Akaike Information Criterion (AIC) and the Schwarz Criterion (SC).

\subsection{Weekly observations of the three-month Treasury bill rate}

Table 2 shows parameter estimates, log likelihood, AIC, and SC for various models evaluated over weekly observations of the three-month Treasury bill rate. Several fitted drift and volatility functions are plotted in Fig. 2.

The affine model, and thus CIR and Vasicek models as well, is overwhelmingly rejected. These models have been used largely because of their analytical tractability. However, they are known to fit the data poorly.

The next set of models uses the constant elasticity of volatility specification together with various parameterizations for the drift. CEV1, which uses a constant drift function, is preferred by all three criteria (AIC, SC, and LR) over the larger CEV models. This finding is particularly remarkable in light of Chapman and Pearson (2000), who argue that there may be a small-sample bias toward finding nonlinearity where none exists.

Table 2

Weekly observations of the three-month Treasury bill rate, January 5, 1962 to August 30, 1996

Parameter estimates and standard errors for the models defined in Table 1 are shown. The Akaike information criterion (AIC) is given by $-2 / n\left[\log \left(\hat{\theta} \mid X_{1}, \ldots, X_{n}\right)-K\right]$ and the Schwarz Criterion (SC) is given by $\log \left(\hat{\theta} \mid X_{1}, \ldots, X_{n}\right)-(K / 2) \log n$, where $K$ is the number of free parameters. The AIC should be minimized, and the SC should be maximized. The likelihood ratio test statistic for comparing nested models is given by $\log L_{u}-\log L_{r} \sim \frac{1}{2} \chi^{2}(\mathrm{df})$, where $\mathrm{df}=$ number of

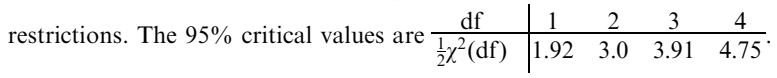

\begin{tabular}{|c|c|c|c|c|c|c|c|c|c|c|c|}
\hline Model & $\log L$ & $-\frac{n}{2} \mathrm{AIC}$ & $\mathrm{SC}$ & $\alpha_{1}$ & $\alpha_{2}$ & $\alpha_{3}$ & $\alpha_{4}$ & $\beta_{1}$ & $\beta_{2}$ & $\beta_{3}$ & $\beta_{4}$ \\
\hline $\mathrm{AFF}$ & 417.15 & 413.15 & 402.15 & $\begin{array}{c}1.2473 \\
(0.3682)\end{array}$ & $\begin{array}{r}-0.1875 \\
(0.0789)\end{array}$ & & & $\begin{array}{c}-1.8091 \\
(0.0338)\end{array}$ & $\begin{array}{c}0.7090 \\
(0.0114)\end{array}$ & & \\
\hline CEV1 & 511.86 & 508.86 & 500.61 & $\begin{array}{c}0.3932 \\
(0.1655)\end{array}$ & & & & $\begin{array}{c}0.1027 \\
(0.0037)\end{array}$ & $\begin{array}{c}1.4531 \\
(0.0204)\end{array}$ & & \\
\hline CEV2 & 512.32 & 508.32 & 497.32 & $\begin{array}{c}0.8277 \\
(0.5004)\end{array}$ & $\begin{array}{r}-0.1049 \\
(0.1167)\end{array}$ & & & $\begin{array}{c}0.1032 \\
(0.0038)\end{array}$ & $\begin{array}{c}1.4502 \\
(0.0210)\end{array}$ & & \\
\hline CEV4 & 512.65 & 506.65 & 490.15 & $\begin{array}{c}-3.6093 \\
(8.1016)\end{array}$ & $\begin{array}{c}0.8382 \\
(1.4646)\end{array}$ & $\begin{array}{c}-0.0593 \\
(0.0798)\end{array}$ & $\begin{array}{c}6.3199 \\
(13.5912)\end{array}$ & $\begin{array}{c}0.1030 \\
(0.0038)\end{array}$ & $\begin{array}{c}1.4515 \\
(0.0210)\end{array}$ & & \\
\hline GEN1 & 513.52 & 508.52 & 494.77 & $\begin{array}{c}0.3978 \\
(0.1678)\end{array}$ & & & & $\begin{array}{c}-0.4011 \\
(0.1620)\end{array}$ & $\begin{array}{c}0.1929 \\
(0.0637)\end{array}$ & $\begin{array}{c}0.0015 \\
(0.0012)\end{array}$ & $\begin{array}{c}3.6648 \\
(0.3391)\end{array}$ \\
\hline GEN2 & 513.99 & 507.99 & 491.49 & $\begin{array}{c}0.8372 \\
(0.5041)\end{array}$ & $\begin{array}{r}-0.1056 \\
(0.1165)\end{array}$ & & & $\begin{array}{c}-0.4084 \\
(0.1625)\end{array}$ & $\begin{array}{c}0.1957 \\
(0.0640)\end{array}$ & $\begin{array}{c}0.0015 \\
(0.0012)\end{array}$ & $\begin{array}{c}3.6647 \\
(0.3427)\end{array}$ \\
\hline GEN4 & 514.26 & 506.26 & 484.26 & $\begin{array}{c}-4.0224 \\
(8.4580)\end{array}$ & $\begin{array}{l}0.8893 \\
(1.5608)\end{array}$ & $\begin{array}{c}-0.0608 \\
(0.0880)\end{array}$ & $\begin{array}{c}7.1945 \\
(13.9818)\end{array}$ & $\begin{array}{c}-0.3959 \\
(0.1664)\end{array}$ & $\begin{array}{c}0.1908 \\
(0.0659)\end{array}$ & $\begin{array}{c}0.0015 \\
(0.0013)\end{array}$ & $\begin{array}{c}3.6474 \\
(0.3518)\end{array}$ \\
\hline
\end{tabular}



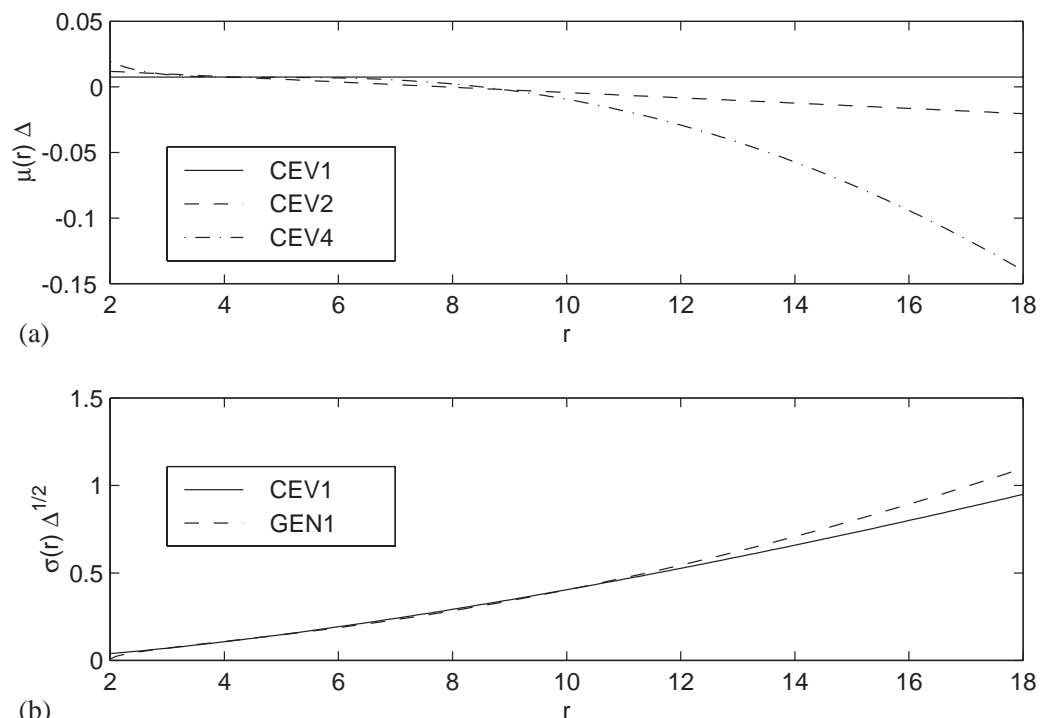

(b)

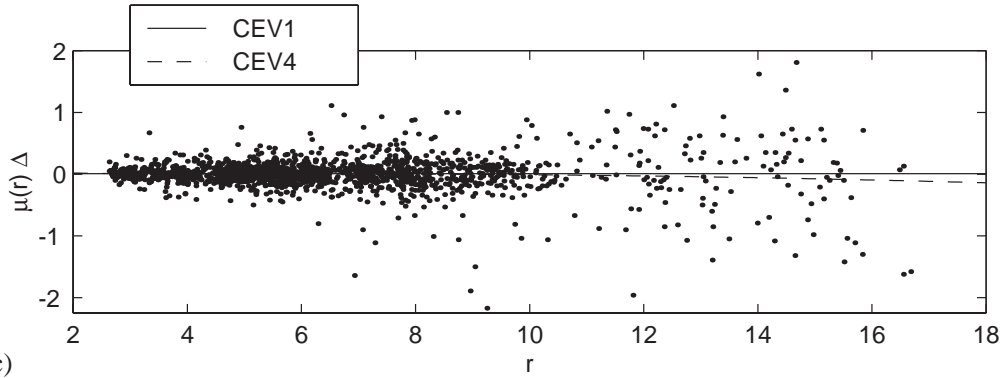

Fig. 2. Fitted drift and volatility functions for weekly Treasury bill data: (a) drift, (b) volatility, and (c) drift superimposed on scatter plot of $r_{t+\Delta}-r_{t}$ versus $r_{t}$.

A Monte Carlo study (available upon request) suggests that the small-sample bias pointed out by Chapman and Pearson exists to some extent even in the maximum likelihood framework. But even without taking this bias into consideration, I find little evidence in favor of nonlinearity.

The various GEN models, which use a more flexible volatility specification, follow a similar pattern: The benefit of going from constant drift to the most general drift specification remains negligible.

Overall, the evidence points heavily in favor of the relatively parsimonious CEV1 model. This is in dramatic contrast to Ait-Sahalia (1996), who finds (using different data and methods) strong evidence for the largest model (GEN4).

In all of the models with free exponents in the volatility function, I am able to estimate the exponent precisely. The exponent in the CEV specification is estimated at 1.45 with a standard error of 0.02 . This estimate is robust to choice of drift specification, and is close to the estimate of 1.5 originally argued for by Chan et al. 
(1992). The precision of the estimate is of particular interest given that several papers using moment-based estimators have found the criterion function to be flat in this dimension (see, e.g., Tauchen, 1995; Conley et al., 1997) and provides a nice demonstration of the relative efficiency of likelihood-based estimation.

Some confusion is found in the literature regarding the issue of stationarity. While a constant drift would seem to imply that the short-rate process is nonstationary, this is not the case. For the CEV1 specification with parameter estimates shown in Table 2 , it is easy to show that stationarity is volatility-induced (see also Conley et al., 1997; Jones, 2003a). Essentially what is happening is that, in the absence of drift, the volatility pushes the process downward. A small positive drift is needed to keep the process from collapsing to zero. For higher levels of the interest rate, the volatility effect dominates, and whether the model exhibits zero, positive, or negative drift makes little difference.

Sufficient conditions for a scalar diffusion process to have a stationary solution are well known (e.g., Karatzas and Shreve, 1991, exercise 5.40). For the CEV2 model with $\beta_{2}>1$, for example, it is sufficient that $\alpha_{1}>0$. There is no restriction on $\alpha_{2}$.

The fitted nonlinear drift that I obtain [Fig. 2(a)] has a shape similar to the drift functions obtained by Aï-Sahalia (1996), Stanton (1997), Ahn and Gao (1999), and others (i.e., positive at low rates, negative at high rates, and near zero in the middle). However, I differ from these papers in interpretation. In particular, I do not find the nonlinearity to be statistically significant. Fig. 2(c), which superimposes the drift plots on top of a scatter plot of $r_{t+\Delta}-r_{t}$ against $r_{t}$, provides intuitive support for this interpretation. Regardless of the specification used, the estimated drift is essentially zero.

Fig. 2(b) shows that the CEV volatility is very close to the more flexible specification through the range where most of the data occurs. The additional flexibility provided by the two additional parameters results in only a small upward shift in the volatility function for high interest rates, where data are relatively scarce. That the simple CEV specification is able to perform so well is remarkable. Again, these plots provide intuitive support for the likelihood-based tests, which unanimously prefer the CEV specification over less parsimonious models.

Fig. 3 displays synthetic data generated using the CEV1, CEV2, and CEV4 models. The plots correspond to 10,000 observations at the weekly frequency (i.e., about 200 years of data). The same sequence of innovations is used to generate each set of data. The data generated by the three models are similar in regions where the interest rate is at levels for which historical data are available. They differ in the extent to which very high interest rates are generated in rare events. Because no empirical observations are available that correspond to such events, the model that one might prefer depends largely on prior beliefs. If one believes that interest rates can virtually never go much above $20 \%$, then the nonlinear drift specification might be appealing.

\subsection{Daily observations of the three-month Treasury bill rate}

Table 3 displays parameter estimates, log likelihood, AIC, and SC for various models estimated over the daily Treasury bill data used by Stanton (1997). 

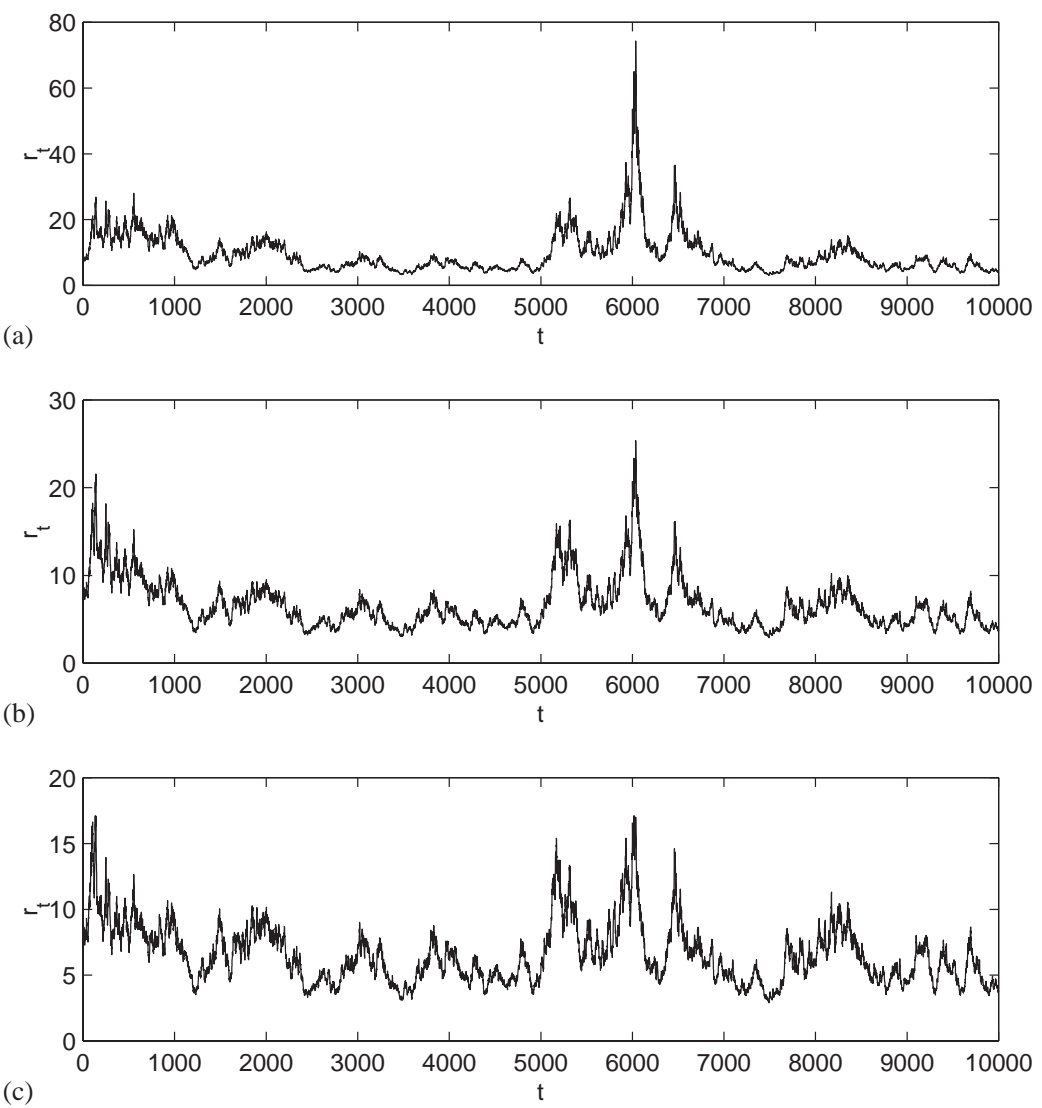

Fig. 3. Synthetic data calibrated to weekly observations of the three-month Treasury bill rate, $N=$ 10,000. This represents about 200 years of synthetic data. Panels (a)-(c) use CEV1, CEV2, and CEV4, respectively.

The findings with respect to the drift are virtually identical to those obtained for the weekly data: negligible evidence exists in favor of including additional terms beyond the constant.

But while the CEV models perform nearly as well as the GEN models over weekly data, they do much worse over daily data. The additional two parameters in the volatility function buy an increase of nearly 50 points in the log likelihood. The fitted volatility functions for CEV1 and GEN1 are shown in Fig. 4. For comparison, a nonparametric fit is also shown. The nonparametric model is estimated by applying a local linear smoother (see, e.g., Fan and Gijbel, 1996) to the squared differences of the data, $\left(r_{t+4}-r_{t}\right)^{2}$.

One is left to speculate as to why the more flexible volatility specification is needed to fit the daily but not the weekly data. The problem is that the CEV volatility function, which is constrained to approach zero at low interest rates, is 
Table 3

Daily observations of the three-month Treasury bill rate, January 4, 1965-July 28, 1995

Parameter estimates and standard errors for the models defined in Table 1 are shown. The Akaike information criterion (AIC) is given by $-2 / n\left[\log \left(\hat{\theta} \mid X_{1}, \ldots, X_{n}\right)-K\right]$ and the Schwarz Criterion (SC) is given by $\log \left(\hat{\theta} \mid X_{1}, \ldots, X_{n}\right)-(K / 2) \log n$, where $K$ is the number of free parameters. The AIC should be minimized, and the SC should be maximized. The likelihood ratio test statistic for comparing nested models is given by $\log L_{u}-\log L_{r} \sim \frac{1}{2} \chi^{2}(\mathrm{df})$, where $\mathrm{df}=$ number of restrictions. The $95 \%$ critical values are \begin{tabular}{c|cccc}
$\mathrm{df}$ & 1 & 2 & 3 & 4 \\
\hline$\frac{1}{2} \chi^{2}(\mathrm{df})$ & 1.92 & 3.0 & 3.91 & $4.75^{\circ}$
\end{tabular}

\begin{tabular}{|c|c|c|c|c|c|c|c|c|c|c|c|}
\hline Model & $\log L$ & $-\frac{n}{2} \mathrm{AIC}$ & $\mathrm{SC}$ & $\alpha_{1}$ & $\alpha_{2}$ & $\alpha_{3}$ & $\alpha_{4}$ & $\beta_{1}$ & $\beta_{2}$ & $\beta_{3}$ & $\beta_{4}$ \\
\hline CEV1 & 7766.55 & 7763.55 & 7753.16 & $\begin{array}{c}0.3498 \\
(0.1902)\end{array}$ & & & & $\begin{array}{c}0.1175 \\
(0.0017)\end{array}$ & $\begin{array}{c}1.3465 \\
(0.0085)\end{array}$ & & \\
\hline CEV2 & 7766.98 & 7762.98 & 7749.12 & $\begin{array}{c}0.8617 \\
(0.5387)\end{array}$ & $\begin{array}{c}-0.1092 \\
(0.1120)\end{array}$ & & & $\begin{array}{c}0.1177 \\
(0.0018)\end{array}$ & $\begin{array}{c}1.3459 \\
(0.0086)\end{array}$ & & \\
\hline CEV4 & 7767.24 & 7761.24 & 7740.45 & $\begin{array}{c}-0.1499 \\
(8.8730)\end{array}$ & $\begin{array}{c}0.2372 \\
(1.4961)\end{array}$ & $\begin{array}{c}-0.0278 \\
(0.0755)\end{array}$ & $\begin{array}{c}0.3271 \\
(15.8000)\end{array}$ & $\begin{array}{c}0.1176 \\
(0.0018)\end{array}$ & $\begin{array}{c}1.3463 \\
(0.0086)\end{array}$ & & \\
\hline GEN1 & 7813.79 & 7808.79 & 7791.47 & $\begin{array}{c}0.3381 \\
(0.2033)\end{array}$ & & & & $\begin{array}{c}0.3633 \\
(0.1114)\end{array}$ & $\begin{array}{r}-0.0262 \\
(0.0430)\end{array}$ & $\begin{array}{c}0.0030 \\
(0.0011)\end{array}$ & $\begin{array}{c}3.3783 \\
(0.1432)\end{array}$ \\
\hline GEN2 & 7814.14 & 7808.14 & 7787.35 & $\begin{array}{c}0.8508 \\
(0.6588)\end{array}$ & $\begin{array}{r}-0.1048 \\
(0.1276)\end{array}$ & & & $\begin{array}{c}0.3613 \\
(0.1113)\end{array}$ & $\begin{array}{c}-0.0254 \\
(0.0430)\end{array}$ & $\begin{array}{c}0.0030 \\
(0.0011)\end{array}$ & $\begin{array}{c}3.3788 \\
(0.1433)\end{array}$ \\
\hline GEN4 & 7814.34 & 7806.34 & 7778.62 & $\begin{array}{l}-3.3157 \\
(10.7120)\end{array}$ & $\begin{array}{c}0.7328 \\
(1.8083)\end{array}$ & $\begin{array}{c}-0.0503 \\
(0.0939)\end{array}$ & $\begin{array}{c}6.2555 \\
(19.4659)\end{array}$ & $\begin{array}{c}0.3667 \\
(0.1118)\end{array}$ & $\begin{array}{r}-0.0275 \\
(0.0432)\end{array}$ & $\begin{array}{c}0.0030 \\
(0.0011)\end{array}$ & $\begin{array}{c}3.3732 \\
(0.1434)\end{array}$ \\
\hline
\end{tabular}

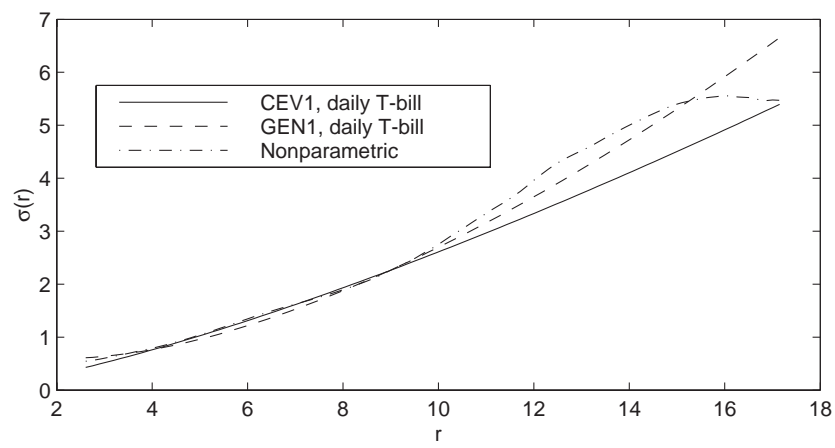

Fig. 4. Comparison of volatility functions for CEV1 and GEN1 models estimated over daily Treasury bill data.

unable to account for the relatively high volatility found in the daily data at low interest rates. Trying to match the low end of the curve causes the CEV volatility function to have too little curvature at high rates. If, for example, the CEV1 and GEN1 models are refitted with the 1,008 observations (out of 7,555) where $r_{t}<4$ is excluded, the difference in log likelihood between the two models is only 7 points.

That different models are needed to fit the data depending upon sampling frequency implies that these single-component Markovian models are misspecified. The models could be extended in several directions to try to capture this behavior. 
One possibility is to let the short rate fluctuate in a narrow band about a slowmoving target rate (the high-frequency fluctuations would tend to disappear as the length of the sampling interval increases). Models of this sort have been examined by Bass and Farnsworth (2000), Piazzesi (2001), Andersen and Lund (1996), Balduzzi et al. (1998), and Jones (2003b).

An easy way to generate discretely sampled data exhibiting high frequency fluctuations about a central tendency is by means of a measurement error model,

$$
\begin{aligned}
& X_{t}=r_{t}+\varepsilon_{t}, \\
& r_{t}=\alpha_{1}+\alpha_{2} r_{t-1}+\beta_{1} r_{t-1}^{\beta_{2}} \eta_{t},
\end{aligned}
$$

where $\varepsilon_{t} \sim \mathrm{N}\left(0, \sigma_{\varepsilon}\right)$ and $\eta_{t} \sim \mathrm{N}(0,1)$. Suppose that $X_{t}$ is the observable proxy for $r_{t}$. Informal experiments suggest that behavior similar to that found empirically can be obtained with $\sigma_{\varepsilon}$ on the order of 0.02 ; i.e., a root mean squared fluctuation of about two basis points. This corresponds to a pricing error of well under one cent on a $\$ 100$ bond with three months to maturity.

The existence of these high-frequency fluctuations suggests that daily data should be used with caution. Ideally, the high-frequency component should be modeled explicitly. This is especially important for modeling very short-term bonds for which the fluctuations can be large (see Section 2.3). At the least, one should consider using a more flexible volatility specification than CEV. Using weekly data simplifies modeling but loses information. There is a tradeoff. The decision on what sampling frequency to use will depend on the particular application.

\subsection{Daily observations of the seven-day Eurodollar rate}

Comparison of the seven-day Eurodollar and three-month Treasury bill data (Fig. 1) immediately suggests that the Eurodollar data are noisy, especially in the early part of the sample. Jumps of 3-5 percentage points in a single day are not uncommon in the Eurodollar data. In contrast, there is only a single jump exceeding two percentage points in a week in the three-month Treasury bill data.

Panels (a) and (b) of Fig. 5 show the Eurodollar and three-month Treasury bill data on the same axes for the years 1980 and 1981, respectively. These plots provide a clearer view of the noise present in the Eurodollar data. They also demonstrate that most of the very high observations of the interest rate in that data are the results of spikes that last only a single day. The highest observed rates are thus almost always followed immediately by large drops. This pattern is largely a feature of the noise component instead of the underlying short-rate process, and will result in a downward bias in the estimated drift at high interest rates.

This effect is different from the one discussed by Chapman and Pearson (2000), who conclude that the particular estimators used by Stanton (1997) and Ait-Sahalia (1996) are likely to find spurious evidence of nonlinearity in the drift because of small-sample bias (even though the samples contain more than 5,000 observations, few observations are made at the high interest rates where the issue of nonlinearity is important). As demonstrated by the results in Sections 2.1 and 2.2, the small sample 


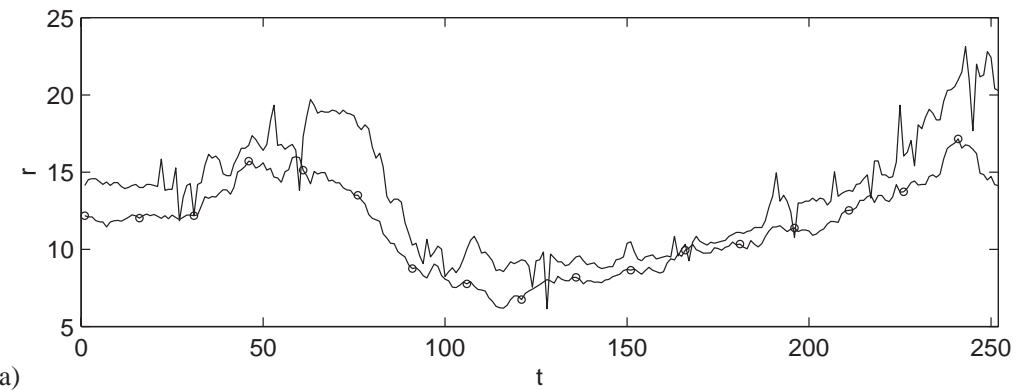

(a)

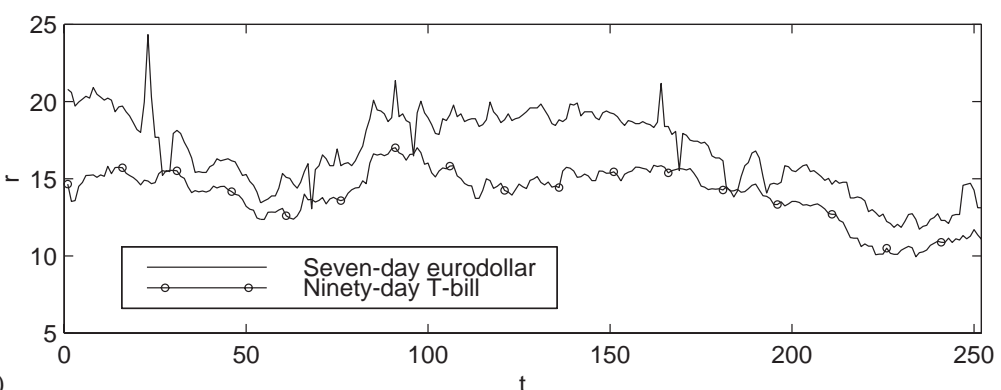

(b)

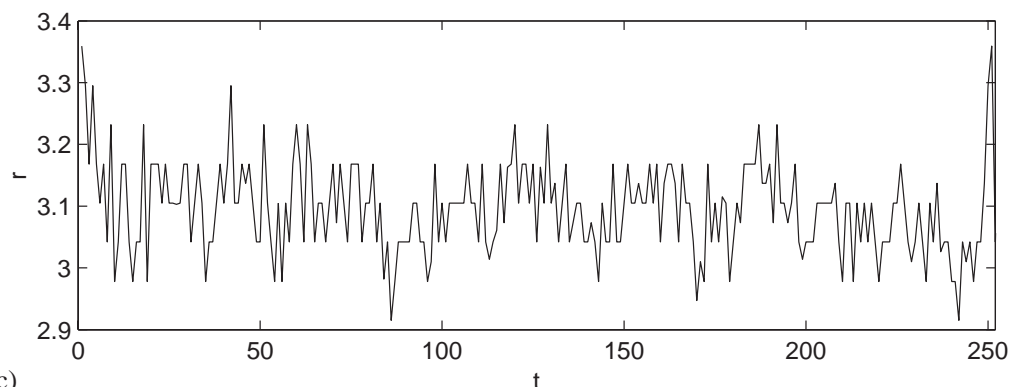

Fig. 5. Daily observations of seven-day Eurodollar and three-month Treasury bill. Data for the years 1980, 1981, and 1993 are shown in panels (a)-(c), respectively. For clarity, panel (c) displays the Eurodollar rates only.

problem does not result in significant evidence of nonlinearity for the three-month Treasury bill data.

Also, Fig. 5(c), which displays the Eurodollar data for 1993, demonstrates that the data for low interest rates are severely contaminated by discreteness effects. The three-month Treasury bill data are omitted from this plot for clarity, but they suffer little from this problem.

The noisiness of very short-term bond yields is a well-known phenomenon. Although the yield may change significantly, little impact is felt on the price of the bond because it is held only for a short time. For this reason, longer-term bonds (e.g., one-month or three-month Treasury bills) are often used as proxies for the short rate (see Chapman et al., 1999, for a discussion of the resulting biases). 
Table 4

Daily observations of the seven-day Eurodollar rate, June 1, 1973 to February 25, 1995.

Parameter estimates and standard errors for the models defined in Table 1 are shown. The Akaike information criterion (AIC) is given by $2 / n\left[\log \left(\hat{\theta} \mid X_{1}, \ldots, X_{n}\right)-K\right]$ and the Schwarz Criterion (SC) is given by $\log \left(\hat{\theta} \mid X_{1}, \ldots, X_{n}\right)-(K / 2) \log n$, where $K$ is the number of free parameters. The AIC should be minimized, and the SC should be maximized. The likelihood ratio test statistic for comparing nested models is given by $\log L_{u}-\log L_{r} \sim \frac{1}{2} \chi^{2}(\mathrm{df})$, where $\mathrm{df}=$ number of restrictions. The $95 \%$ critical values are \begin{tabular}{c|cccc}
$\mathrm{df}$ & 1 & 2 & 3 & 4 \\
\hline$\frac{1}{2} \chi^{2}(\mathrm{df})$ & 1.92 & 3.0 & 3.91 & $4.75^{\circ}$
\end{tabular}

\begin{tabular}{|c|c|c|c|c|c|c|c|c|c|c|c|}
\hline Model & $\log L$ & $-\frac{n}{2} \mathrm{AIC}$ & $\mathrm{SC}$ & $\alpha_{1}$ & $\alpha_{2}$ & $\alpha_{3}$ & $\alpha_{4}$ & $\beta_{1}$ & $\beta_{2}$ & $\beta_{3}$ & $\beta_{4}$ \\
\hline CEV1 & -961.11 & -964.11 & -974.03 & $\begin{array}{c}1.9351 \\
(0.6700)\end{array}$ & & & & $\begin{array}{c}0.2897 \\
(0.0051)\end{array}$ & $\begin{array}{c}1.3560 \\
(0.0087)\end{array}$ & & \\
\hline CEV2 & -960.76 & -964.76 & -977.99 & $\begin{array}{c}3.1769 \\
(1.6232)\end{array}$ & $\begin{array}{c}-0.2495 \\
(0.3005)\end{array}$ & & & $\begin{array}{l}0.2906 \\
(0.0051)\end{array}$ & $\begin{array}{c}1.3545 \\
(0.0087)\end{array}$ & & \\
\hline CEV4 & -957.54 & -963.54 & -983.38 & $\begin{array}{r}-29.3131 \\
(5.3062)\end{array}$ & $\begin{array}{c}5.8966 \\
(0.5410)\end{array}$ & $\begin{array}{r}-0.3307 \\
(0.0011)\end{array}$ & $\begin{array}{c}50.0541 \\
(11.9785)\end{array}$ & $\begin{array}{c}0.2894 \\
(0.0051)\end{array}$ & $\begin{array}{c}1.3568 \\
(0.0087)\end{array}$ & & \\
\hline GEN1 & -942.61 & -947.61 & -964.14 & $\begin{array}{r}0.49843 \\
(0.2391)\end{array}$ & & & & $\begin{array}{r}-5.4489 \\
(0.3959)\end{array}$ & $\begin{array}{c}2.2971 \\
(0.1146)\end{array}$ & $\begin{array}{c}0.0012 \\
(0.0003)\end{array}$ & $\begin{array}{c}4.2310 \\
(0.1071)\end{array}$ \\
\hline GEN2 & -941.09 & -947.09 & -966.93 & $\begin{array}{c}3.4128 \\
(1.6677)\end{array}$ & $\begin{array}{c}-0.2619 \\
(0.3004)\end{array}$ & & & $\begin{array}{c}-5.4482 \\
(0.4701)\end{array}$ & $\begin{array}{c}2.2983 \\
(0.1395)\end{array}$ & $\begin{array}{c}0.0012 \\
(0.0004)\end{array}$ & $\begin{array}{c}4.2310 \\
(0.1376)\end{array}$ \\
\hline GEN4 & -938.70 & -946.70 & -973.15 & $\begin{array}{r}-28.8908 \\
(0.6235)\end{array}$ & $\begin{array}{c}5.6030 \\
(0.0650)\end{array}$ & $\begin{array}{c}-0.3119 \\
(0.0001)\end{array}$ & $\begin{array}{c}52.4248 \\
(1.0170)\end{array}$ & $\begin{array}{c}-5.3686 \\
(0.2538)\end{array}$ & $\begin{array}{c}2.2718 \\
(0.0636)\end{array}$ & $\begin{array}{c}0.0013 \\
(0.0001)\end{array}$ & $\begin{array}{c}4.2011 \\
(0.0300)\end{array}$ \\
\hline
\end{tabular}

Clearly, the simple scalar processes considered in this section are poorly equipped to model the sort of transient spikes common in the seven-day Eurodollar data. A careful analysis should probably include an additional component to model the highfrequency fluctuations, as discussed in Section 2.2 (see also Jones, 2003b).

Panels (a) and (b) of Fig. 5 also show a significant difference in the levels of the Treasury bill and Eurodollar rates. This difference is frequently in the range of 2-4 percentage points. It is almost certainly too large to be attributed to the term structure and is more likely the result of institutional or microstructure effects of some sort (e.g., Longstaff (2000) points out that short-term Treasury-bill rates may be lower than the true riskless rate).

Despite the problems with the Eurodollar data, I estimate several of the models shown in Table 4 in order to better evaluate the results of Ait-Sahalia (1996).

As with the daily Treasury bill data, the CEV models are soundly beaten by the models using the more general volatility specification. I estimate the elasticity of volatility at about 1.35 for the CEV models, which is virtually identical to that of the daily Treasury bill data. However, the coefficient of the volatility term is over twice as large for the Eurodollar data as compared with the Treasury bill data ( 0.29 versus 0.12$)$. Fig. 6 plots estimated volatility functions for the three data sets on the same set of axes. The difference in the volatility of the Treasury bill and Eurodollar data is clearly evident. Note that the frequency at which the Treasury bill data is sampled makes comparatively little difference. This provides reassurance that sampling frequency is not at the root of the much higher volatility exhibited by the Eurodollar data.

Fig. 7(b) compares my estimated volatility function for the GEN4 model with the one reported by Aït-Sahalia (1996). These fits are quite different. Aït-Sahalia finds 


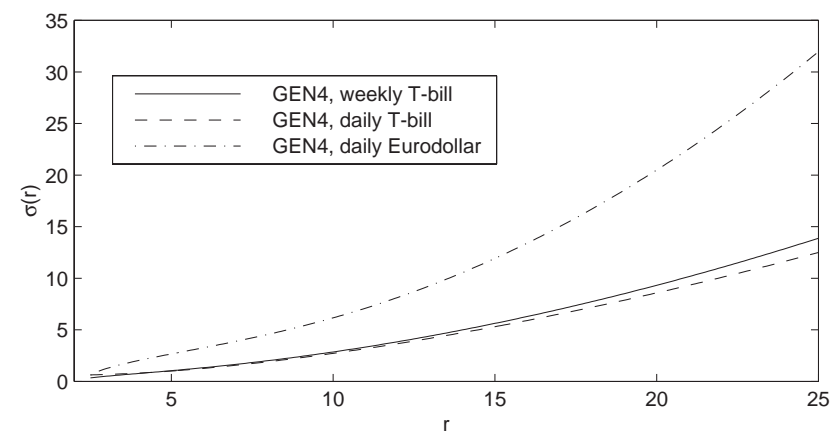

Fig. 6. Comparison of volatility functions for GEN4 model over seven-day Eurodollar and three-month Treasury bill data.

that volatility is lowest when the short rate is around $10-12 \%$ and that volatility is about the same when the short rate is at $3 \%$ as when it is at $18 \%$. It is difficult to see much evidence for Ait-Sahalia's estimates in the scatter plot shown in Fig. 7(d). They are also counterintuitive.

For the drift function, there is more evidence in favor of nonlinearity than with either of the Treasury bill series, but none of the additional terms beyond the constant is significant at the $95 \%$ level (LR test).

Fig. 7(a) compares Aït-Sahalia's estimated drift function for the GEN4 model with that of this paper. My drift function exhibits much stronger nonlinearity (albeit statistically insignificant) than does that of Aït-Sahalia. Aït-Sahalia's estimated nonlinear drift function is positive for interest rates up to $22 \%$ (interest rates greater than $22 \%$ were observed on only four days). In any event, Fig. 7(c) shows that, as with the Treasury bill data, the drift is essentially zero regardless of specification.

\section{Stochastic volatility models}

While being able to accurately evaluate scalar models is an essential first step, the short rate (along with many other financial time series) is known to exhibit properties such as fat tails and persistant volatility patterns that are inconsistent with these models. A variety of latent variable models have been proposed as alternatives. In this section, I consider models of the form

$$
\begin{aligned}
& \mathrm{d} X=\mu_{X}(X) \mathrm{d} t+\sigma_{X}(X) \exp (H) \mathrm{d} W_{1} \\
& \mathrm{~d} H=\mu_{H}(H) \mathrm{d} t+\sigma_{H}(H) \mathrm{d} W_{2} .
\end{aligned}
$$

The second factor corresponds to the unobserved volatility.

To obtain a likelihood, the unobserved factor must be integrated out. For discrete time models, several approaches have been proposed (e.g., Danielson and Richard, 1993; Richard and Zhang, 2000; Durbin and Koopman, 1997; Kim et al., 1998; Pitt 


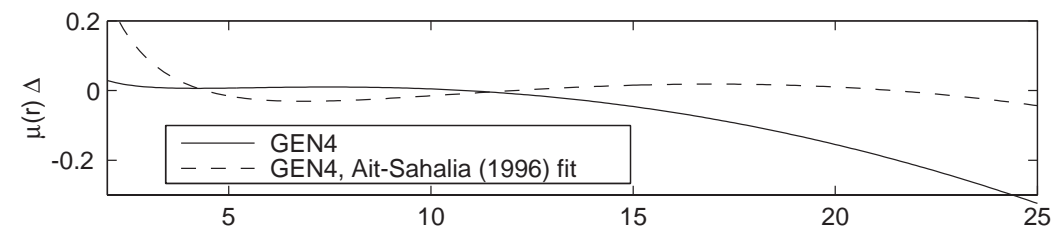

(a)
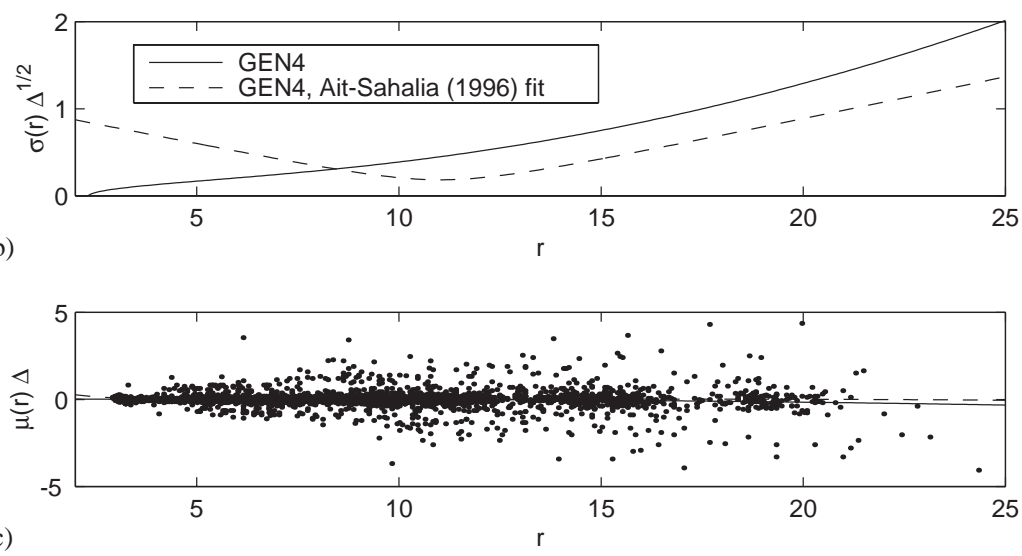

(c)

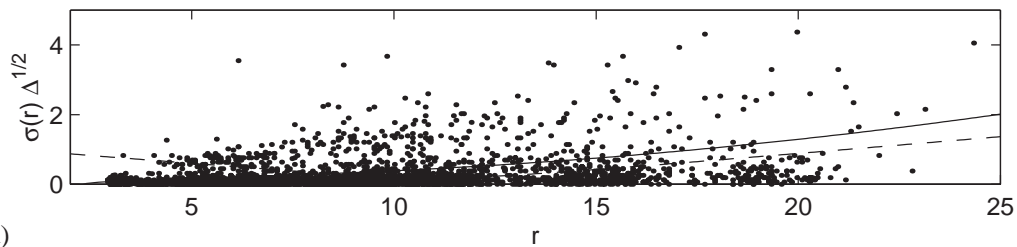

Fig. 7. Drift and volatility of Eurodollar data: (a) estimated drift function for the GEN4 model; (b) volatility function for GEN4 model; and (c) and (d) are the same as panels (a) and (b) except superimposed on scatter plots of $r_{t+\Delta}-r_{t}$ and $\left|r_{t+\Delta}-r_{t}\right|$ against $r_{t}$, respectively.

and Shephard, 1999). In the continuous-time context, this has not been feasible until recently and alternative approaches have been used. The efficient method of moments approach has been used by Gallant and Tauchen (1998) and others. Methods based on the empirical characteristic function have been proposed by Chacko and Viceira (2003) and Singleton (2001). Markov Chain Monte Carlo approaches have been used by Jones (2003a), Elerian (1999), and Eraker (2001). Another approach to estimating the volatility process is to use the information present in high-frequency data (e.g., Andersen et al., 2001). Alizadeh et. al. (2002) suggest a technique using information from the high-low range.

The approach used in this paper does compute the likelihood of the continuoustime latent factor model. The latent variable is integrated out using a technique based on particle filtering (see, e.g., Pitt and Shephard, 1999, and the references 
therein). Given draws from the latent variable, one proceeds as before by simulating paths across unobserved values of the state variable at intermediate points between each pair of observations. Computational cost is relatively low, with reasonably accurate estimates obtained within several minutes. A detailed description of the methodology may be found in Durham and Gallant (2002). For simplicity, I assume that $W_{1}$ and $W_{2}$ are independent.

One of the nice features of the estimation technique proposed by Durham and Gallant (2002) is that estimates of the latent volatility process $H_{1}, \ldots, H_{n}$ are readily available. This is highly useful for pricing derivative securities.

Parameter estimates for several models over weekly observations of the threemonth Treasury bill rate from January 5, 1962 to August 30, 1996 (as used in Section 2) are shown in Table 5. All of these models result in a huge jump in the likelihood as compared with the scalar models considered in Section 2. As with the scalar models, the evidence in favor of nonlinearity in $\mu_{X}$ is negligible. The CEV parameters $\beta_{1}$ and $\beta_{2}$ are close to those found for the scalar model. The parameter $\gamma$, which determines the rate of mean reversion for $H$, is about 4 , implying that innovations have a halflife of around two months. Several more flexible specifications for $\sigma_{H}$, the volatility of volatility, were tried, but none was found to provide a significant improvement over the models shown in Tables 5 and 6 .

\section{Implications for bond pricing}

This section examines bond-pricing implications of some of the models considered in previous sections. Consider first the single factor model

$$
\mathrm{d} r=\mu(r) \mathrm{d} t+\sigma(r) \mathrm{d} W
$$

and suppose that $P(r, \tau)$ is the price of a security whose value depends on only the spot rate and time to maturity. Given standard regularity conditions, Ito's rule implies

$$
\begin{aligned}
\mathrm{d} P & =P_{r} \mathrm{~d} r-P_{\tau} \mathrm{d} t+\frac{1}{2} \sigma^{2} P_{r r} \mathrm{~d} t \\
& =\left[\mu(r) P_{r}-P_{\tau}+\frac{1}{2} \sigma^{2}(r) P_{r r}\right] \mathrm{d} t+\sigma(r) P_{r} \mathrm{~d} W .
\end{aligned}
$$

Standard no-arbitrage arguments (see, e.g., Duffie, 1992) imply that the expected excess return of $P$ should equal the security's factor loading times the associated market price of risk; i.e.,

$$
\mu(r) P_{r}-P_{\tau}+\frac{1}{2} \sigma^{2}(r) P_{r r}=r P+\lambda(r) P_{r},
$$

where $\lambda(r)$ is the market price of risk. This may be rewritten as

$$
\tilde{\mu}(r) P_{r}-P_{\tau}+\frac{1}{2} \sigma^{2}(r) P_{r r}=r P,
$$

where $\tilde{\mu}=\mu(r)-\lambda(r)$. One typically refers to $\tilde{\mu}$ as the risk-neutral drift and to

$$
\mathrm{d} r=\tilde{\mu}(r) \mathrm{d} t+\sigma(r) \mathrm{d} W
$$


Table 5

Stochastic volatility models

The specifications of each of the models considered in this section are shown together with the labels by which they are referred in the text.

\begin{tabular}{ll}
\hline SV1: & $\mathrm{d} X=\alpha_{1} \mathrm{~d} t+\beta_{1} X^{\beta_{2}} \mathrm{e}^{H} \mathrm{~d} W_{1}$ \\
& $\mathrm{~d} H=\gamma H \mathrm{~d} t+\delta \mathrm{d} W_{2}$ \\
SV2: & $\mathrm{d} X=\left(\alpha_{1}+\alpha_{2} X\right) \mathrm{d} t+\beta_{1} X^{\beta_{2}} \mathrm{e}^{H} \mathrm{~d} W_{1}$ \\
& $\mathrm{~d} H=\gamma H \mathrm{~d} t+\delta \mathrm{d} W_{2}$ \\
SV3: & $\mathrm{d} X=\left(\alpha_{1}+\alpha_{2} X+\alpha_{3} X^{2}+\alpha_{4} / X\right) \mathrm{d} t+\beta_{1} X^{\beta_{2}} \mathrm{e}^{H} \mathrm{~d} W_{1}$ \\
& $\mathrm{~d} H=\gamma H \mathrm{~d} t+\delta \mathrm{d} W_{2}$ \\
\hline
\end{tabular}

Table 6

Stochastic volatility models over weekly observations of the three-month Treasury bill rate, January 5 , 1962 to August 30, 1996

\begin{tabular}{llcccccccc}
\hline Model & $\log L$ & $\alpha_{1}$ & $\alpha_{2}$ & $\alpha_{3}$ & $\alpha_{4}$ & $\beta_{1}$ & $\beta_{2}$ & $\gamma$ & $\delta$ \\
\hline SV1 & 913.92 & 0.250 & & & & 0.097 & 1.292 & -4.077 & 1.683 \\
& & $(0.100)$ & & & & $(0.028)$ & $(0.162)$ & $(0.744)$ & $(0.139)$ \\
SV2 & 913.93 & 0.188 & 0.016 & & & 0.098 & 1.287 & -4.099 & 1.685 \\
& & $(0.295)$ & $(0.067)$ & & & $(0.028)$ & $(0.159)$ & $(0.745)$ & $(0.140)$ \\
SV3 & 913.99 & -0.168 & 0.027 & 0.003 & 0.952 & 0.100 & 1.276 & -4.035 & 1.676 \\
& & $(5.395)$ & $(0.998)$ & $(0.057)$ & $(8.940)$ & $(0.029)$ & $(0.162)$ & $(0.740)$ & $(0.140)$ \\
\hline
\end{tabular}

as the risk-neutral process. For clarity, Eq. (8) is often referred to as the physical or objective process.

Given $\tilde{\mu}(\cdot), \sigma(\cdot)$, and a boundary condition, the partial differential equation Eq. (11) can be used to compute $P$. Alternatively, given some observations of $P$, one can estimate $\tilde{\mu}$ and $\sigma$. In practice, a convenient way to solve for $P$ is by means of the Feynman-Kac formulation

$$
P(r, \tau)=\mathrm{E}^{R N}\left[B \mathrm{e}^{-\int_{0}^{\tau} r(u) \mathrm{d} u}+\int_{0}^{\tau} C(s) \mathrm{e}^{-\int_{0}^{s} r(u) \mathrm{d} u} \mathrm{~d} s\right],
$$

where $B$ is the terminal payoff of the security at maturity, $C(s)$ is the cash flow paid out by the security, and the expectation is taken under the risk-neutral dynamics (see, e.g., Karatzas and Shreve, 1991). If $P$ is the price of a zero coupon bond that pays out $\$ 1$ in all states at time $T$, this simplifies to

$$
P(r, \tau)=\mathrm{E}^{R N}\left[\mathrm{e}^{-\int_{0}^{\tau} r(u) \mathrm{d} u}\right] .
$$

Either Eq. (13) or (14) is easy to compute using Monte Carlo techniques.

For multifactor models, suppose that $r(X)$ and $P(X)$ are both functions of a state vector $X=\left(X_{1}, X_{2}, \ldots, X_{K}\right)$ satisfying

$$
\mathrm{d} X=\mu(X) \mathrm{d} t+\sigma(X) \mathrm{d} W,
$$


where now $\mu$ is $K$-dimensional, $\sigma$ is $K \times L$-dimensional and $W$ is $L$-dimensional. A similar argument to that above holds. The result is again Eq. (13), but in this case the expectation is taken over $r(X)$ according to the risk-neutral dynamics

$$
\mathrm{d} X=\tilde{\mu}(X) \mathrm{d} t+\sigma(X) \mathrm{d} W,
$$

where $\tilde{\mu}(X)=\mu(X)-\lambda(X)$ and $\lambda$ is the vector of risk prices associated with $X$.

Table 7 shows parameter estimates for several models of the physical and riskneutral processes using data obtained via the Nelson-Siegel-Bliss methodology described in Bliss (1997) and implemented in software available from Bliss. This data consists of 2,064 observations each for the yields of three-month and one, two, five, and ten-year zero coupon bonds at a weekly frequency over the period June 16, 1961 to December 29, 2000. The three-month bond serves as a proxy for the risk-free rate.

The risk-neutral models are estimated by minimizing squared pricing errors. Given a parameter vector $\theta$ and the spot rate, Eq. (14) is used to compute the implied prices of bonds with maturity $m=1,2,5$, and 10 years. Let $P_{t}(m)$ denote the observed price of a $\$ 1$ bond at time $t$ and $\tilde{P}(r, m ; \theta)$ denote the implied price. The idea is to minimize the criterion function

$$
\hat{\theta}=\underset{\theta}{\operatorname{argmin}} \sum_{\substack{t=1, \ldots, T \\ m=1,2,5,10}}\left(\tilde{P}\left(r_{t}, m ; \theta\right)-P_{t}(m)\right)^{2} .
$$

An alternative approach would be to minimize the errors in implied yields. One might also try different weighting schemes. Using a standard GMM-style weighting matrix would place most of the weight on short-term bonds (because they have much smaller pricing errors). It is unclear whether this is desirable from an economic point of view (see, e.g., Cochrane, 2001). The approach described by Eq. (17) is simple, intuitively appealing, and robust. In any event, the results do not appear to be sensitive to the particular weighting scheme used.

As with the physical process, little is gained by including additional terms beyond a constant in the drift. Adding a stochastic volatility component also provides little improvement in bond-pricing performance. Notice that $\alpha_{3}$, the coefficient of $H$ in the drift of the observed component of the SV-RN model, is significantly positive. This corresponds to a positive risk premium for the latent volatility component. The mean reversion parameter of the latent component is large, which implies that the impact of spot volatility on bond prices dissipates rapidly. Physical and risk-neutral drift functions for the single factor models are plotted in Fig. 8. The market price of risk can be obtained via the identity $\lambda(r)=\mu(r)-\tilde{\mu}(r)$.

A nonparametric estimate of the market price of risk can be computed as follows. Suppose that the price of a security satisfies

$$
\mathrm{d} P=\mu_{*}(r) \mathrm{d} t+\sigma_{*}(r) \mathrm{d} W .
$$

Comparing Eqs. (9) and (18), one obtains

$$
\sigma_{*}(r)=\sigma(r) P_{r} .
$$


Table 7

Estimation results for physical and risk-neutral models, Nelson-Siegel-Bliss data, June 16, 1961 to December 29, 2000

\begin{tabular}{|c|c|c|c|c|c|c|c|}
\hline \multicolumn{8}{|c|}{ Physical models } \\
\hline Model & $\log \mathrm{L}$ & $\alpha_{1}$ & $\alpha_{2}$ & $\alpha_{3}$ & $\alpha_{4}$ & $\beta_{1}$ & $\beta_{2}$ \\
\hline CEV1 & 796.07 & $\begin{array}{c}0.3919 \\
(0.1368)\end{array}$ & & & & $\begin{array}{c}0.1034 \\
(0.0034)\end{array}$ & $\begin{array}{c}1.4003 \\
(0.0181)\end{array}$ \\
\hline CEV2 & 796.94 & $\begin{array}{c}0.8918 \\
(0.3725)\end{array}$ & $\begin{array}{r}-0.1211 \\
(0.0903)\end{array}$ & & & $\begin{array}{c}0.1038 \\
(0.0034)\end{array}$ & $\begin{array}{c}1.3977 \\
(0.0183)\end{array}$ \\
\hline CEV4 & 797.07 & $\begin{array}{r}-0.8101 \\
(4.4979)\end{array}$ & $\begin{array}{c}0.2730 \\
(0.8868)\end{array}$ & $\begin{array}{r}-0.0265 \\
(0.0511)\end{array}$ & $\begin{array}{c}2.1768 \\
(6.7726)\end{array}$ & $\begin{array}{c}0.1037 \\
(0.0034)\end{array}$ & $\begin{array}{c}1.3984 \\
(0.0187)\end{array}$ \\
\hline Model & $\log L$ & $\alpha_{1}$ & $\alpha_{2}$ & $\beta_{1}$ & $\beta_{2}$ & $\gamma$ & $\delta$ \\
\hline SV2 & 1261.16 & $\begin{array}{c}0.2027 \\
(0.2527)\end{array}$ & $\begin{array}{c}0.0295 \\
(0.0570)\end{array}$ & $\begin{array}{c}0.0803 \\
(0.0192)\end{array}$ & $\begin{array}{c}1.3425 \\
(0.1340)\end{array}$ & $\begin{array}{r}-5.6435 \\
(0.8730)\end{array}$ & $\begin{array}{c}1.9870 \\
(0.1397)\end{array}$ \\
\hline
\end{tabular}

Risk-natural models

\begin{tabular}{lccccc}
\hline Model & RMSE $^{\mathrm{a}}$ & $\alpha_{1}$ & $\alpha_{2}$ & $\alpha_{3}$ & $\alpha_{4}$ \\
\hline $\mathrm{CEV}^{\mathrm{b}}$ & 0.0353 & 0.3614 & & & \\
& & $(0.0247)$ & & & \\
$\mathrm{CEV}^{\mathrm{b}}{ }^{\mathrm{b}}$ & 0.0351 & 0.4700 & -0.0182 & & \\
& & $(0.1031)$ & $(0.0167)$ & & \\
$\mathrm{CEV}^{\mathrm{b}}{ }^{\mathrm{b}}$ & 0.0350 & 0.2771 & 0.0494 & -0.0045 & $(2.6486)$
\end{tabular}

\begin{tabular}{lcccccc} 
Model & RMSE $^{\mathrm{a}}$ & $\alpha_{1}$ & $\alpha_{2}$ & $\alpha_{3}$ & $\gamma_{1}$ & $\gamma_{2}$ \\
\hline SV-RN $^{\mathrm{c}}$ & 0.0340 & 7.6878 & -0.0453 & 14.5699 & -20.3447 & -9.9618 \\
& & $(1.8570)$ & $(0.0150)$ & $(3.6913)$ & $(4.5587)$ & $(2.4160)$ \\
\hline
\end{tabular}

${ }^{\mathrm{a}} \mathrm{RMSE}=\left(1 / 4 T \sum_{\substack{t=1, \ldots, T \\ m=1,2,5,10}}\left(\tilde{P}\left(r_{t}, m ; \hat{\theta}\right)-P_{t}(m)\right)^{2}\right)^{1 / 2}$.

${ }^{\mathrm{b}}$ Computed with $\beta_{1}=0.1038$ and $\beta_{2}=1.3977$ fixed.

${ }^{\mathrm{c}}$ The SV-RN model is given by

$$
\begin{aligned}
\mathrm{d} r & =\left(\alpha_{1}+\alpha_{2} r+\alpha_{3} H\right) \mathrm{d} t+\beta_{1} r^{\beta_{2}} \mathrm{e}^{H} \mathrm{~d} W_{1} \\
\mathrm{~d} H & =\left(\gamma_{1} H+\gamma_{2}\right) \mathrm{d} t+\delta \mathrm{d} W_{2} .
\end{aligned}
$$

Estimates are computed with $\beta_{1}=0.0803, \beta_{2}=1.3425$, and $\delta=1.9870$ fixed.

Recalling that the expected excess return of a security should equal its factor loading times $\lambda$,

$$
\mu_{*}(r)-r=\lambda(r) P_{r},
$$

one can eliminate $P_{r}$, yielding

$$
\lambda(r)=\left(\mu_{*}(r)-r\right) \sigma(r) / \sigma_{*}(r) .
$$



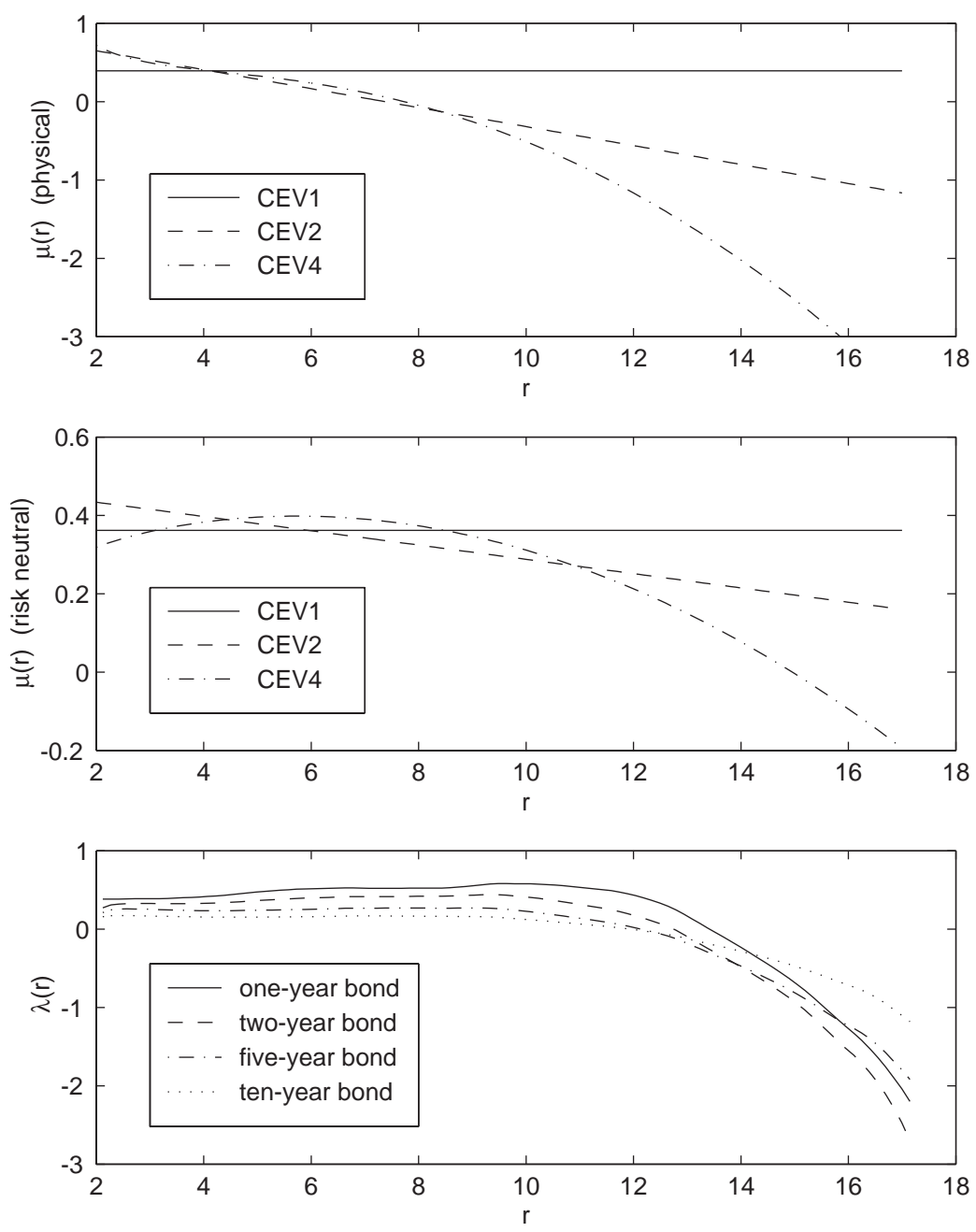

Fig. 8. Drift of physical and risk-neutral single component models and nonparametric estimate of market price of risk, Nelson-Siegel-Bliss data, June 16, 1961 to December 29, 2000.

Each of the functions on the right-hand side of Eq. (21) is estimated using a local linear smoother on the first-order approximation of the continuous-time model (see, e.g., Fan and Gijbel, 1996). This is similar to the approach suggested by Stanton (1997).

The result is four different estimates for $\lambda(r)$, one for each maturity considered. Fig. 8(c) shows that the nonparametric estimates depend strikingly little upon the maturity of the bond used in the computation. If these estimates differed significantly, it would provide evidence against the single factor model (for a formal test of this hypothesis, see Cheng, 2001). 


\section{Conclusions}

While there is a great deal of interest in using stochastic differential equations to model financial time series data, it has been difficult to find effective ways to estimate these models. This paper demonstrates procedures by which highly accurate approximations to the maximum likelihood estimator may be quickly and conveniently obtained.

In addition to the wellknown optimality properties of MLE, availability of the likelihood provides a convenient tool for specification analysis. Although the data and models examined in this paper are for the most part well known, the statistical techniques are novel and allow a number of new, and in some cases surprising, results to be obtained.

Several models for the risk-neutral measure are estimated by minimizing the squared differences between observed and implied bond prices. Computing the bond prices implied by stochastic volatility models requires estimates of the spot volatility. A convenient feature of my estimation procedure is that volatility estimates are readily available.

While adding the latent volatility component provides a large improvement in the likelihood as compared with single component models for the physical process, it does little to improve bond-pricing performance.

\section{References}

Ahn, D.-H., Gao, B., 1999. A parametric nonlinear model of term structure dynamics. Review of Financial Studies 12, 721-762.

Ahn, D.-H., Dittmar, R.F., Gallant, A.R., 2002. Quadratic term structure models: theory and evidence. Review of Financial Studies 15, 243-288.

Ait-Sahalia, Y., 1996. Testing continuous-time models of the spot interest rate. Review of Financial Studies 9, 385-426.

Aït-Sahalia, Y., 1999. Transition densities for interest rate and other nonlinear diffusions. Journal of Finance 54, 1361-1395.

Aït-Sahalia, Y., 2001. Maximum likelihood estimation of discretely sampled diffusions: a closed-form approach. Econometrica 70, 223-262.

Alizadeh, S., Diebold, F.X., Brandt, M.W., 2002. Range-based estimation of stochastic volatility models. Journal of Finance 57, 1047-1091.

Andersen, T.G., Lund, J., 1996. Stochastic volatility and mean drift in the short term interest rate diffusion: sources of steepness, level, and curvature in the yield curve. Unpublished working paper. Northwestern University.

Andersen, T.G., Lund, J., 1997. Estimating continuous-time stochastic volatility models of the short-term interest rate. Journal of Econometrics 77, 343-377.

Andersen, T.G., Bollerslev, T., Diebold, F.X., Labys, P., 2001. The distribution of realized exchange rate volatility. Journal of the American Statistical Association 96, 42-55.

Balduzzi, P., Das, S., Foresi, S., 1998. The central tendency: a second factor in bond yields. Review of Economics and Statistics 80, 62-72.

Bass, R., Farnsworth, H., 2000. The term structure with semi-credible targeting. Unpublished working paper. Washington University-St. Louis.

Bibby, B.M., Sørensen, M., 1995. Martingale estimating functions for discretely observed diffusion processes. Bernoulli 1, 17-39. 
Bliss, R.R., 1997. Testing term structure estimation methods. Advances in Futures and Options Research 9, 197-231.

Boudoukh, J., Richardson, M., Stanton, R., Whitelaw, R.F., 1998. The stochastic behavior of interest rates: implications from a multifactor, nonlinear continuous-time model. Unpublished working paper. University of California-Berkeley.

Brandt, M.W., Santa-Clara, P., 2002. Simulated likelihood estimation of diffusions with an application to exchange rate dynamics in incomplete markets. Journal of Financial Economics 63, 161-210.

Chacko, G., 1996. Multifactor interest rate dynamics and their implications for bond pricing. Unpublished working paper. Harvard University.

Chacko, G., Viceira, L.M., 2003. Spectral GMM estimation of continuous-time processes. Journal of Econometrics 116, 259-292.

Chan, K.C., Karolyi, G.A., Longstaff, F.A., Sanders, A.B., 1992. An empirical comparison of alternative models of the short-term interest rate. Journal of Finance 47, 1209-1228.

Chapman, D.A., Pearson, N.D., 2000. Is the short-rate drift actually nonlinear? Journal of Finance 55, 355-388.

Chapman, D.A., Long Jr., J.B., Pearson, N.D., 1999. Using proxies for the short rate: when are three months like an instant? Review of Financial Studies 12, 763-806.

Cheng, A.-R., 2001. No-arbitrage testing with single factor: a nonparametric approach. Unpublished working paper. University of North Carolina.

Cochrane, J.H., 2001. Asset Pricing. Princeton University Press, Princeton, New Jersey.

Conley, T.G., Hansen, L.P., Luttmer, E.G.J., Scheinkman, J.A., 1997. Short-term interest rates as subordinated diffusions. Review of Financial Studies 10, 525-577.

Cox, J.C., Ingersoll, J.E., Ross, S.A., 1985. A theory of the term structure of interest rates. Econometrica 53, 385-407.

Dai, Q., Singleton, K.J., 2000. Specification analysis of affine term structure models. Journal of Finance 55, 1943-1978.

Danielson, J., Richard, J.-F., 1993. Accelerated Gaussian importance sampler with application to dynamic latent variable models. Journal of Applied Econometrics 8, 153-173.

Duffie, D., 1992. Dynamic Asset Pricing Theory. Princeton University Press, Princeton, New Jersey.

Duffie, D., Glynn, P., 1996. Estimation of continuous-time Markov processes sampled at random time intervals. Unpublished working paper. Stanford University.

Duffie, D., Kan, R., 1996. A yield-factor model of interest rates. Mathematical Finance 6, 379-406.

Duffie, D., Singleton, K.J., 1993. Simulated moments estimation of Markov models of asset prices. Econometrica 61, 929-952.

Durbin, J., Koopman, S., 1997. Monte Carlo maximum likelihood estimation for non-Gaussian state space models. Biometrika 84, 669-684.

Durham, G.B., Gallant, A.R., 2002. Numerical techniques for simulated maximum likelihood estimation of stochastic differential equations. Journal of Business and Statistics 20, 297-316.

Elerian, O., 1998. A note on the existence of a closed form conditional transition density for the Milstein scheme. Unpublished working paper. Nuffield College, Oxford University.

Elerian, O., 1999. Simulation estimation of continuous-time models with applications to finance. Ph.D. Dissertation, Nuffield College, Oxford University.

Elerian, O., Chib, S., Shephard, N., 2001. Likelihood inference for discretely observed non-linear diffusions. Econometrica 69, 959-993.

Eraker, B., 2001. MCMC analysis of diffusion models with application to finance. Journal of Business and Economic Statistics 19, 177-191.

Fan, J., Gijbel, I., 1996. Local Polynomial Modeling and Its Applications. Chapman \& Hall, London.

Florens-Zmirou, D., 1989. Approximate discrete-time schemes for statistics of diffusion processes. Statistics 20, 547-557.

Gallant, A.R., Tauchen, G., 1997. Estimation of continuous-time models for stock returns and interest rates. Macroeconomic Dynamics 1, 135-168.

Gallant, A.R., Tauchen, G., 1998. Reprojecting partially observed systems with application to interest rate diffusions. Journal of the American Statistical Association 93, 10-24. 
Ghysels, E., Harvey, A., Renault, E., 1996. Stochastic volatility. In: Maddala, G.S., Rao, C.R. (Eds.), Handbook of Statistics, Vol. 14, Statistical Methods in Finance. North-Holland, Amsterdam.

Gouriéroux, C., Monfort, A., Renault, E., 1993. Indirect inference. Journal of Applied Econometrics 8, S85-S118.

Hansen, L.P., Scheinkman, J.A., 1995. Back to the future: generating moment implications for continuous-time Markov processes. Econometrica 63, 767-804.

Jones, C.S., 1999. Bayesian estimation of continuous-time finance models. Unpublished working paper. University of Rochester.

Jones, C.S., 2003a. The dynamics of stochastic volatility. Journal of Econometrics 116, 181-224.

Jones, C.S., 2003b. Nonlinear mean reversion in the short-term interest rate. Review of Financial Studies, forthcoming.

Karatzas, I., Shreve, S.E., 1991. Brownian Motion and Stochastic Calculus, 2nd Edition. Springer, New York

Kessler, M., 1997. Estimation of an ergodic diffusion from discrete observations. Scandinavian Journal of Statistics 24, 211-229.

Kim, S., Shephard, N., Chib, S., 1998. Stochastic volatility: likelihood inference and comparison with ARCH models. Review of Economic Studies 65, 361-393.

Lehmann, E.L., 1986. Testing Statistical Hypotheses, 2nd Edition. Wiley, New York.

Longstaff, F.A., 2000. The term structure of very short-term rates: new evidence for the expectations hypothesis. Journal of Financial Economics 58, 397-415.

Nowman, K., 1997. Gaussian estimation of single-factor continuous time models of the term structure of interest rates. Journal of Finance 52, 1695-1706.

Pedersen, A.R., 1995. A new approach to maximum likelihood estimation for stochastic differential equations based on discrete observations. Scandinavian Journal of Statistics 22, 55-71.

Piazzesi, M., 2001. An econometric model of the yield curve with macroeconomic jump effects. Unpublished working paper. University of California-Los Angeles.

Pitt, M.K., Shephard, N., 1999. Filtering via simulation: auxiliary particle filter. Journal of the American Statistical Association 446, 590-599.

Pritsker, M., 1998. Nonparametric density estimation and tests of continuous time interest rate models. Review of Financial Studies 11, 449-487.

Richard, J.-F., Zhang, W., 2000. Accelerated Monte Carlo integration: an application to dynamic latent variables models. In: Mariano, R.S., Schuermann, T., Weeks, M. (Eds.), Simulation-Based Inference in Economics. Cambridge University Press, Cambridge, U.K, pp. 47-70.

Santa-Clara, P., 1995. Simulated likelihood estimation of diffusions with an application to the short-term interest rate. Ph.D. Dissertation. INSEAD.

Shoji, I., Ozaki, T., 1998. Estimation for nonlinear stochastic differential equations by a local linearization method. Stochastic Analysis and Applications 16, 733-752.

Singleton, K.J., 2001. Estimation of affine asset pricing models using the empirical characteristic function. Journal of Econometrics 102, 111-141.

Stanton, R., 1997. A nonparametric model of term structure dynamics and the market price of interest rate risk. Journal of Finance 52, 1973-2002.

Tauchen, G.E., 1995. New minimum chi-square methods in empirical finance. In: Wallace, K., Kreps, D. (Eds.), Advances in Econometrics. Cambridge University Press, Cambridge, U.K, pp. 279-317.

Vasicek, O., 1977. An equilibrium characterization of the term structure. Journal of Financial Economics $5,177-188$. 